\title{
EXPERIMENTAL ASSESSMENT AND NUMERICAL MODELLING OF SELF HEALING CAPACITY OF CEMENT BASED MATERIALS VIA FRACTURE MECHANICS CONCEPTS
}

\author{
LIBERATO FERRARA ${ }^{*}$, GIOVANNI DI LUZIO ${ }^{\dagger}$ AND VISAR KRELANI ${ }^{\dagger \dagger}$ \\ Politecnico di Milano, Department of Civil and Environmental Engineering \\ Milano, Italy \\ e-mail: liberato.ferrara@polimi.it \\ ${ }^{\dagger}$ Politecnico di Milano, Department of Civil and Environmental Engineering \\ Milano, Italy \\ e-mail: giovanni.diluzio@polimi.it \\ ${ }^{\dagger}$ University for Business and Technology, Kalabria, \\ Prishtine, Kosovo \\ e-mail: vkrelani@ubt-uni.net
}

Key words: Self-healing, Crystalline admixtures, Mechanical properties regain

\begin{abstract}
The authors' research group has undertaken for about a lustrum a comprehensive research project, focusing on both experimental characterization and numerical predictive modelling of the self-healing capacity of a broad category of cementitious composites, ranging from normal strength concrete to high performance cementitious composites reinforced with different kinds of industrial (steel) and natural fibers. In this paper reference will be made to normal strength concrete: both autogenous healing capacity has been considered and self-healing engineered through the use of crystalline admixtures. A tailored methodology has been employed to characterize the healing capacity of the investigated concrete, based on comparative evaluation of the mechanical performance measured through 3-point bending tests. Tests have been performed to pre-crack the specimens to target values of crack opening, and after scheduled conditioning times to selected exposure conditions, including water immersion and exposure to open air. The healing capacity has been quantified by means of the definition and calculation of suitable "healing indices", based on the recovery of the mechanical properties, including load bearing capacity, stiffness, ductility, toughness etc. and correlated to the amount of crack closure also "estimated" through suitable indirect methodologies. Chemical characterization of the healing products by means of SEM has been performed to understand the different mechanisms governing the observed phenomena and also discriminate among the different amounts of recovery of the different mechanical properties. As a further step a predictive modelling approach, based on modified microplane model, has been formulated. This incorporates the self-healing effects, in particular, the delayed cement hydration, as well as the effects of cracking on the diffusivity and the opposite repairing effect of the self-healing on the micro-plane model constitutive laws. The whole experimental and numerical investigation represents a comprehensive and solid step towards the reliable and consistent incorporation of self-healing concepts and effects into a durability-based design framework for engineering applications made of or retrofitted with self-healing concrete and cementitious composites.
\end{abstract}




\section{INTRODUCTION}

Sustainability has to become the "ethos" that defines "how we should act, individually and together, to protect and propagate our environment, harness our knowledge, share insights and technologies to build tomorrow while reducing the burden" on today [1]. fib Model Code 2010 has explicitly and firmly recognized sustainability as the "fourth pillar" which has to inform, together with the "classical" requisites of safety, serviceability and durability, the concept, design, construction, maintenance/use and, in case, deconstruction and reuse of any civil and building engineering application.

The porous structure of concrete is one of the main causes of its proneness to degradation. Even if it is generally accepted that a well-proportioned and properly cured concrete, produced using a low water to cement $(\mathrm{w} / \mathrm{c})$ ratio, can result in a finished product with good durability, no concrete material can be made absolutely waterproof or "bottle tight". In fact, because of the porous structure of concrete, water can penetrate through pores and micro-cracks, due to either capillary absorption or (and) hydrostatic pressure. In this framework, together with the already well "acquired" ability to design and cast a concrete as compact and impervious as possible, the engineering community would keenly look for any effective, easily implementable, durable and "repeatable" technology which would make such a concrete also able to activate, upon cracking, selfrepairing mechanisms. These mechanisms should also be able to restore to their pristine level the set of engineering properties, which are relevant to the intended applications [2]. "If the mechanism of the action is understood, and means can be found for accelerating it, a great stride will have been made in effectively retarding" the rate of degradation of concrete and corrosion of embedded steel reinforcement, which are the major problems of the concrete durability $[3,4]$.

Autogenous healing of concrete was reportedly discovered as early as in 1836 by the French Academy of Science, and attributed to the transformation of calcium hydroxide $\left(\mathrm{Ca}(\mathrm{OH})_{2}\right)$ into calcium carbonate $\left(\mathrm{CaCO}_{3}\right)$ as a consequence of exposure to the carbon dioxide $\left(\mathrm{CO}_{2}\right)$ in the atmosphere. Later, Abrams [5] attributed self-healing to the "hydraulicity" of residual un-hydrated cement, and Loving [6], who, on inspection of concrete pipe culverts, found many healed cracks filled with calcium carbonate.

As a matter of fact, besides the availability of $\mathrm{CO}_{2}$ in the exposure environment, the age of concrete at the time of cracking also governs the mechanism with the highest autogenous healing capacity. Due to its relatively high content of un-hydrated cement particles, ongoing/delayed hydration is the main healing mechanism in young concrete [79], whereas at a later age, calcium carbonate precipitation becomes the major one.

The action of autogenous healing may have "practical value in several applications (...) namely: (...) repair of precast units cracked during early handling; sealing against corrosion and re-knitting of cracks developed in concrete piles during their handling and driving; sealing of cracks in concrete water tanks; and the regain, after loss, of strength and stiffness of "green" concrete disturbed by vibrations" $[10,11]$.

Anyway, whereas significant reduction in water permeability was observed because of crack healing [12-14], reported recovery of mechanical properties $[3,14,15]$ was not so spectacular. With reference to the maximum crack width that can be healed without any external intervention, a wide range of openings has been reported by different authors (from as low as 5 to as high as 300 microns) [16-18].

RILEM TC-221-SHC [1], distinguishes:

- based on the result of the action, between self-closing and self-healing, whether only closure of the cracks or also restoring of the mechanical properties is observed;

based on the process of the action, between "autogenic/autogenous" (or natural) and "autonomic" (or engineered) selfclosing/healing, whether the crack closure or restoration of material properties is due to 
either the concrete material itself or some engineered addition.

In the very last decade a huge amount of research work has been dedicated to "engineered" self-healing, along different directions of investigation: self-healing engineered with fibre reinforcement [20-28], mineral-producing bacteria [29], super absorbent polymers [30], healing agents contained in shell and tubular capsules [31, 32] and other proprietary chemical admixtures [33]. In the latter case, the self-healing action is mainly due to the filling of the crack width, swelling and expansion effects and to improved hydration and re-crystallization. The supply of water (moisture) is essential, especially in the case of addition of chemical agents able to promote the deposition of crystals inside the crack, but "since most infrastructures are exposed to rain or underground water, usually this is an easily satisfiable requirement" [33]. Besides the presence of water, several other variables can affect the phenomenon of self-healing, such as the mix proportions [15], the stress state along the cracks and the steadiness of the cracked state [19] as well as thermal and hygrometric conditions $[3,16]$. Traditional mineral additions for cement replacement, such as fly ash or blast furnace slag, [34, 35] or innovative pozzolanic additions [36, 37], investigated by different researchers, may also promote autogenous healing because of delayed hydration, since high amounts of these binders remain un-hydrated even at a later age because of the slow pozzolanic reactions or, as in the case of slag, because of latent hydraulicity.

Among the aforementioned proprietary chemical admixtures, special attention has been deserved in recent years to the so-called crystalline admixture, which are a category of Permeability Reducing Admixtures already available and widely employed as such in the construction products market.

Crystalline admixture generally consist of a proprietary mix of active chemicals, carried in a carrier of cement and sand, which, because of their highly hydrophyllic nature, are able to react with water, cement particles but also with the soluble phase of cement hydration products
$\left(\mathrm{Ca}(\mathrm{OH})_{2}\right)$ and form Calcium Silicate Hydrates (C-S-H) and other pore blocking precipitates. These reaction products, on the one hand, increase the density of the C-S-H phase, and, on the other, deposit in the existing capillaries and micro-cracks activating the self-repairing process. The mechanism is analogous to the formation of $\mathrm{C}-\mathrm{S}-\mathrm{H}$ and the resulting crystalline deposits become integrally bound with the hydrated cement paste. Furthermore, hairline cracks are formed over the life of concrete, and because of that, it would be also desirable that crystalline admixtures store certain delayed self-healing capacity for further cracks. That capacity would ideally contribute to a recovery of the engineering and mechanical properties of the composite, also as a function of the exposure conditions and durations and of the activated healing mechanisms. Anyway, cracks exceed-ing the self-sealing or self-healing capacity of the concrete may still be developed.

In this paper the results of an experimental investigation will be presented, with reference to self-healing in Normal Strength Concrete (NSC), autogenous and engineered through crystalline admixtures. The methodology employed to characterize the effects of healing, which stands as a key feature of the study, is based on the tailored experimental identification of the recovery of mechanical properties (load bearing capacity), through which also an indirect assessment of the crack closure could be accomplished.

As a further step a predictive modelling approach, based on modified micro-plane model, has been formulated. This incorporates the self-healing effects, in particular, the delayed cement hydration, as well as the effects of cracking on the diffusivity and the opposite repairing effect of the self-healing on the micro-plane model constitutive laws.

The whole experimental and numerical investigation represents a solid step towards the reliable and consistent incorporation of self-healing concepts into a durability-based design framework for engineering applications made of or retrofitted with self-healing concrete and cement-based materials. 


\section{EXPERIMENTAL PROGRAM}

The employed crystalline admixture consists of a blend of cement, sand and microsilica; SEM magnified particles are shown in Figures 1a-b: they have irregular shape and size in the range of about 1-20 $\square \mathrm{m}$ and their morphology is similar to that of cement grains; EDS analysis confirmed the presence of calcium, oxygen, silicon, magnesium, aluminium and potassium (Figure 1c). This spectrum is comparable with that of an Ordinary Portland Cement (OPC), except for the slightly higher peak of sulphur.

The employed NSC composition is shown in Table 1. Specimens $500 \mathrm{~mm}$ long x $100 \mathrm{~mm}$ wide $\mathrm{x} 50 \mathrm{~mm}$ thick, were cut from larger slabs $(1 \mathrm{~m} \times 0.5 \mathrm{~m})$ casted with that mix. After 35 to 42 days curing in a fog room at $20^{\circ} \mathrm{C}$ and 95\% relative humidity, specimens were precracked by means of a COD-controlled 3-point bending (3pb) set-up (450 mm span - Figure $2)$, up to about $250 \mu \mathrm{m}$. Specimens were then either immersed in water at $20^{\circ} \mathrm{C}$ or exposed to open air, with daily recording of temperature (ranging all along the year between $-5^{\circ} \mathrm{C}$ and $40^{\circ} \mathrm{C}$ ) and relative humidity (ranging between $50 \%$ and $100 \%$ ). After scheduled exposure times (1, 3, 6 and 12 months) 3-point bending tests were performed again on the same specimens according to the same set-up and results between the pre- and post-conditioning response were compared, in order to evaluate, if any, load-bearing capacity and stiffness recovery and calculate related "self-healing indices".

Table 2 reports a synopsis of the program.

Table 1: Mix composition of the employed NSCs

\begin{tabular}{ccc}
\hline Constituent & $\begin{array}{c}\text { W/out } \\
\text { additive }\end{array}$ & $\begin{array}{c}\text { With } \\
\text { additive }\end{array}$ \\
\hline Cement type II 42.5 & 300 & 300 \\
\hline Water & 190 & 190 \\
\hline $\begin{array}{c}\text { Superplasticizer } \\
\left(1 \mathrm{t} / \mathrm{m}^{3}\right)\end{array}$ & 3 & 3 \\
\hline $\begin{array}{c}\text { Fine aggregate 0-4 } \\
\text { mm }\end{array}$ & 1078 & 1080 \\
\hline $\begin{array}{c}\text { Coarse aggregate 4- } \\
16 \text { mm }\end{array}$ & 880 & 880 \\
\hline Crystalline additive & $=$ & 3 \\
\hline
\end{tabular}

Table 2: Synopsis of the experimental program

\begin{tabular}{|c|c|c|c|c|c|c|c|c|c|c|c}
\hline & \multicolumn{1}{c}{ Water immersion } & \multicolumn{1}{c}{ Air exposure } \\
\hline & $\mathbf{1 m}$ & $\mathbf{2 m}$ & $\mathbf{3 m}$ & $\mathbf{6 m}$ & $\mathbf{1 2 m}$ & $\mathbf{1 m}$ & $\mathbf{2 m}$ & $\mathbf{3 m}$ & $\mathbf{6 m}$ & $\mathbf{1 2 m}$ \\
\hline & With crystalline admixture \\
\hline Uncracked & $\mathbf{1}$ & $\mathbf{2}$ & $\mathbf{2}$ & $\mathbf{2}$ & $\mathbf{2}$ & $\mathbf{1}$ & $\mathbf{2}$ & $\mathbf{2}$ & $\mathbf{2}$ & $\mathbf{2}$ \\
\hline Wrecracked 200 $\mu \mathrm{m}$ & $\mathbf{1}$ & $\mathbf{2}$ & $\mathbf{2}$ & $\mathbf{2}$ & $\mathbf{2}$ & $\mathbf{1}$ & $\mathbf{2}$ & $\mathbf{2}$ & $\mathbf{2}$ & $\mathbf{2}$ \\
\hline \multicolumn{10}{|c|}{ Without crystalline admixture } \\
\hline uncracked & $\mathbf{1}$ & $\mathbf{2}$ & $\mathbf{2}$ & $\mathbf{2}$ & $\mathbf{2}$ & $\mathbf{1}$ & $\mathbf{2}$ & $\mathbf{2}$ & $\mathbf{2}$ & $\mathbf{2}$ \\
\hline Precracked 200 $\mu \mathrm{m}$ & $\mathbf{1}$ & $\mathbf{2}$ & $\mathbf{2}$ & $\mathbf{2}$ & $\mathbf{2}$ & $\mathbf{1}$ & $\mathbf{2}$ & $\mathbf{2}$ & $\mathbf{2}$ & $\mathbf{2}$ \\
\hline
\end{tabular}

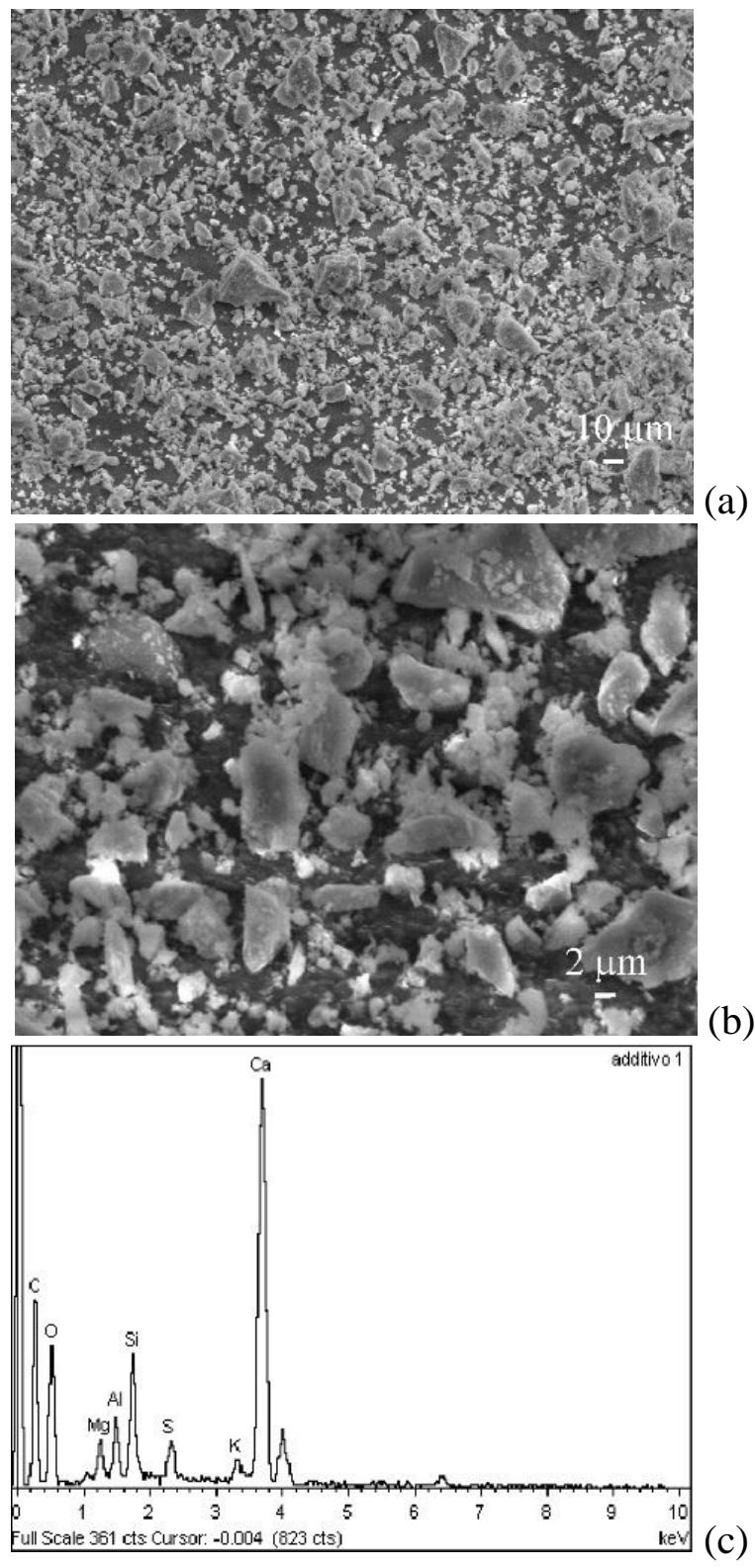

Figure 1: SEM magnification (a,b) and EDS analysis (c) of the employed crystalline admixture particles.

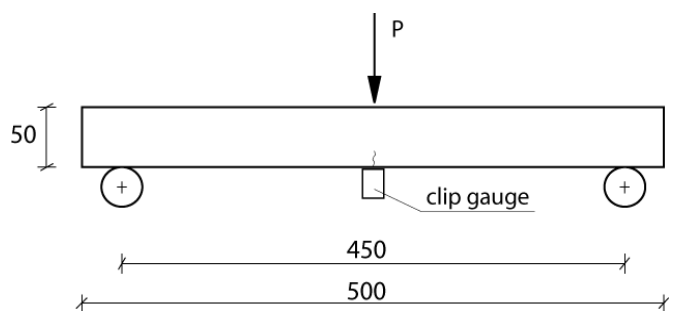

Figure 2: Scheme of the employed 3-pb test set-up. 


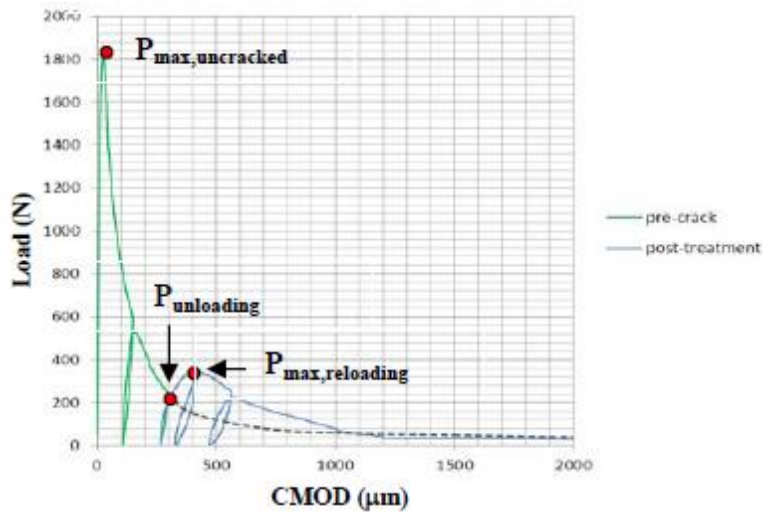

Figure 3: Example of stress vs. COD curves for specimens submitted to pre-cracking and postconditioning $3 \mathrm{pb}$ tests.

\section{EXPERIMENTAL RESULTS}

In Figure 3 the results of a typical test, in terms of nominal stress $\sigma_{N}$ vs. COD curves, are shown: the graphs are built up to compare the curves pertaining respectively to the precracking test and to the post-conditioning upto-failure test for the same specimens.

From the values of nominal bending stresses and flexural stiffness, as denoted in Figure 3, an Index of Stress Recovery (ISR) and Index of Damage Recovery (IDR) have been defined and calculated as follows:

$$
\begin{array}{r}
\text { ISR }=\frac{\mathrm{P}_{\text {max reloading }}-\mathrm{P}_{\text {unloading }}}{\mathrm{P}_{\text {cmax, uncracked }}-\mathrm{P}_{\text {unloading }}} \\
\mathrm{IDR}=\frac{\mathrm{K}_{\text {reloading,post-conditioning }}-\mathrm{K}_{\text {unloadingpre-crack }}}{\mathrm{K}_{\text {loading,yirginspeeimen }}-\mathrm{K}_{\text {unloadingpre-crack }}}
\end{array}
$$

Figures 4 a-b show the trend of both indices vs. the exposure time for different exposure conditions. The following remarks hold:

- specimens immersed in water and made with concrete containing the crystalline additive exhibited an almost immediate and quite significant recovery, which even upon prolonged exposure, showed continuing improvement of the recovered performance; on the other hand specimens made with plain concrete and immersed in water (squares Figure 4a) showed a more gradual recovery, which anyway, even after six months, barely attained half the level achieved by concrete with the crystalline additive;

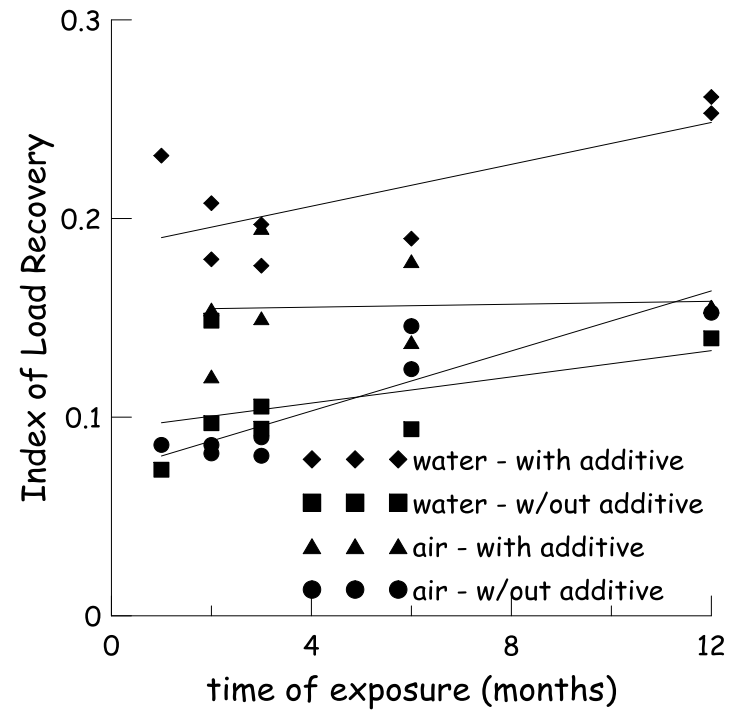

(a)

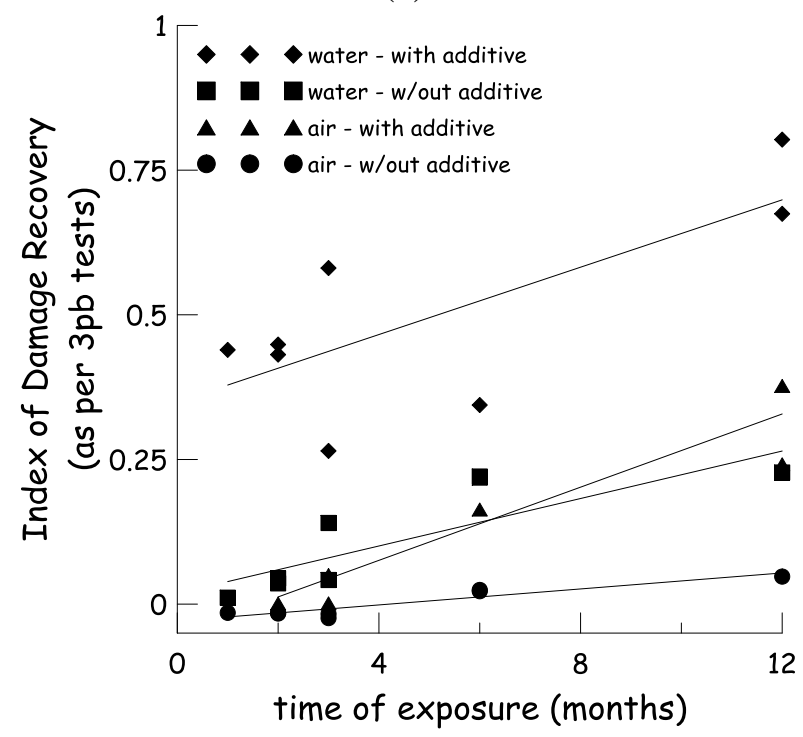

(b)

Figure 4: Indices of Stress (a) and Damage Recovery (b) vs. exposure time

- specimens exposed to open air and made with concrete containing the crystalline additive showed a gradual recovery capacity, as high as the one exhibited by plain concrete specimens immersed in water; on the contrary a scant recovery capacity at all was exhibited by specimens without the additive (maximum 5\% after twelve months).

Pictures obtained by stereo-microscope in Figures 5 a-d and with SEM and related EDS analysis in Figures 6 a-b confirm the aforementioned statements and are as well coherent with the analyzed EDS spectrum of the admixture as shown in Figure 1c. 

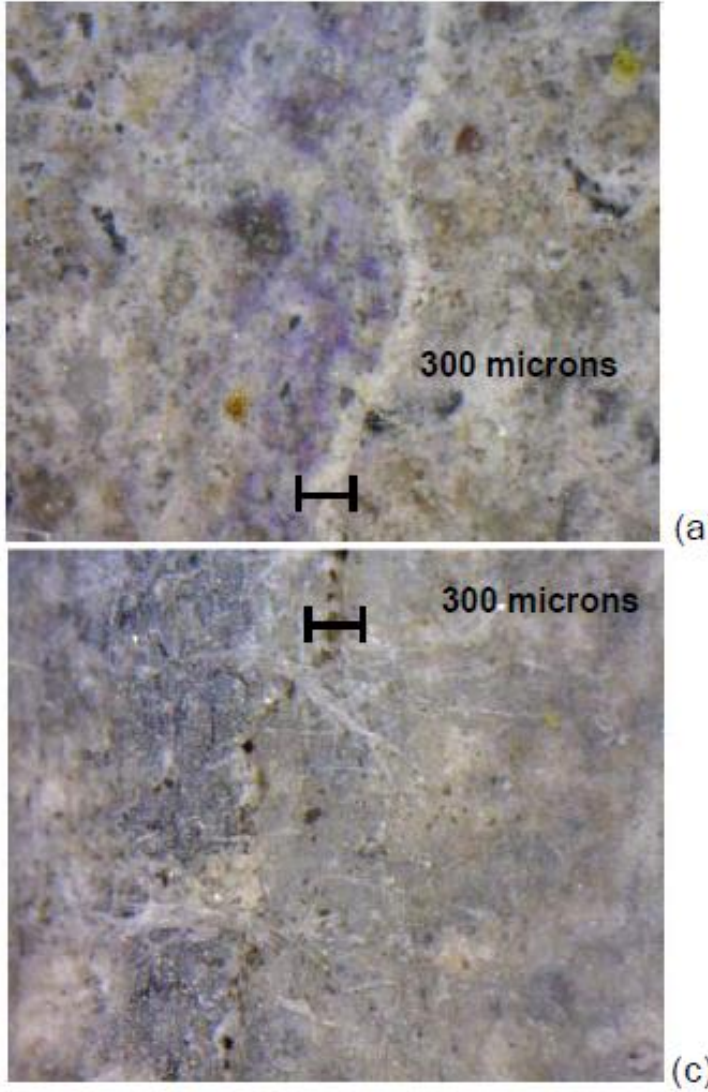

(a)
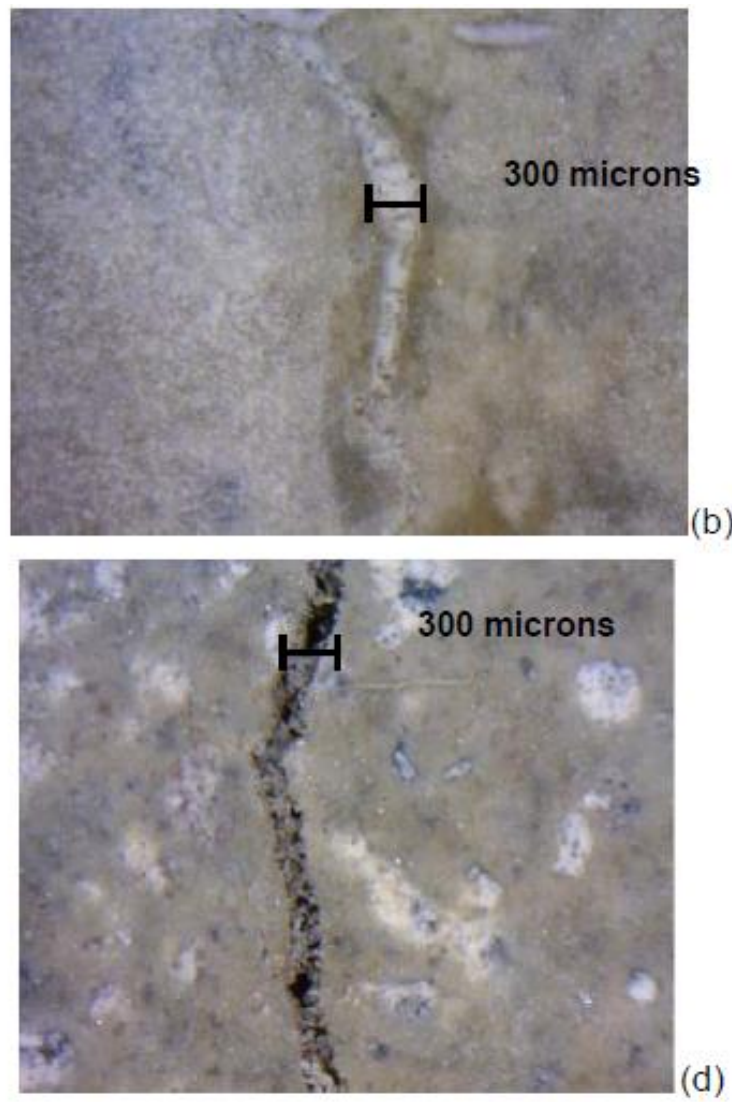

(d)

Figure 5: healed/healing cracks for specimens with $(a, c)$ and without $(b, c)$ crystalline additive after six months of immersion in water $(\mathrm{a}, \mathrm{b})$ and exposure to air $(\mathrm{c}, \mathrm{d})$.
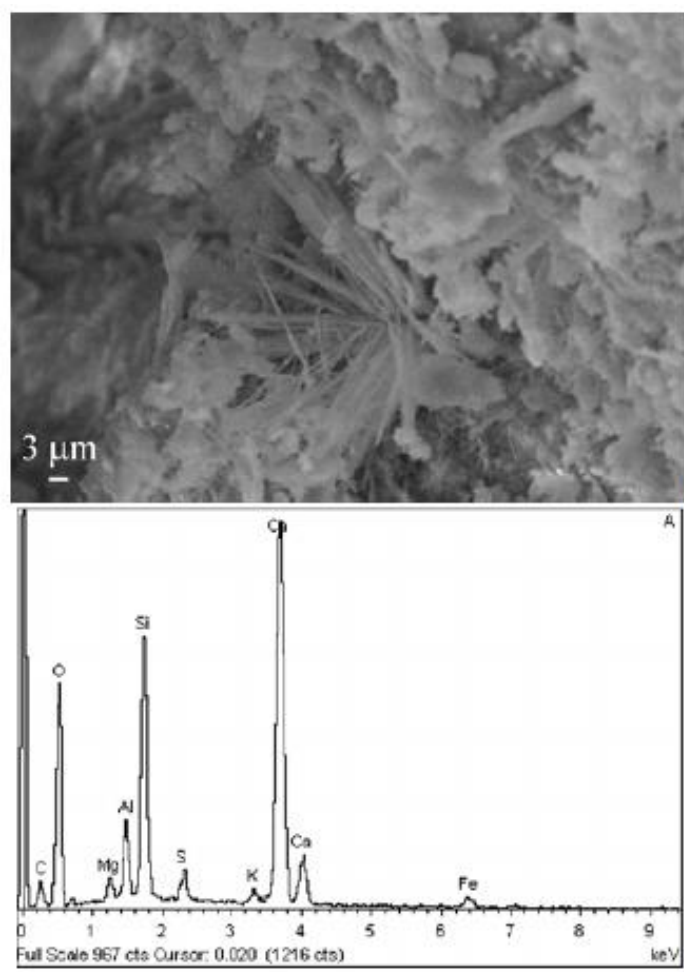

(a)
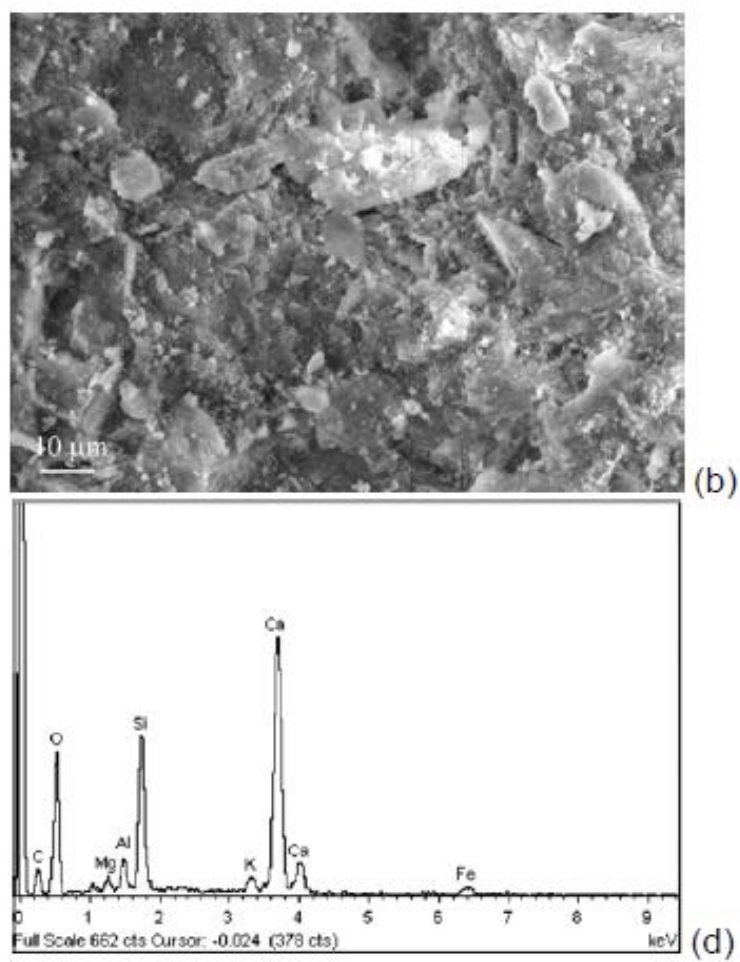

(b)

Figure 6: SEM images and EDS analyses for specimens with $(a, c)$ and without $(b, c)$ crystalline additive after three months of immersion in water. 


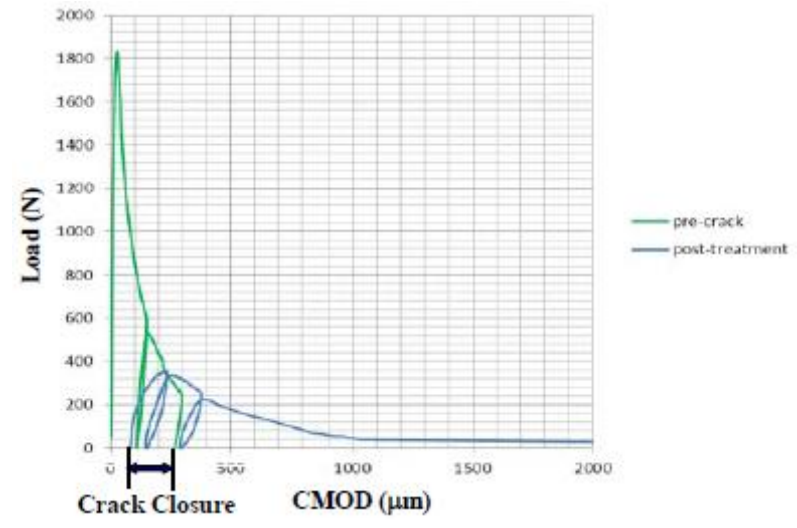

Figure 7: Graphical explanation of the procedure to estimate crack closure from $\sigma_{\mathrm{N}}-\mathrm{COD}$ curves.

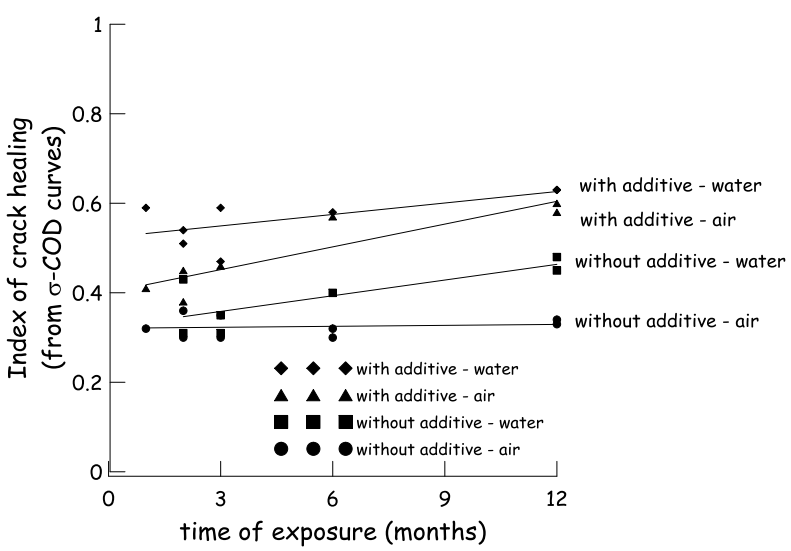

Figure 8: Index of Crack Healing vs. exposure time.

From the nominal bending stress $\sigma_{N}$ vs. COD curves an estimation of the crack closure due to the self-healing can be provided. The proposed methodology (Figure 7a) consists in operating a "backward" shifting along the COD axis, of the stress-COD curve representative of the behavior of each precracked specimen after environment conditioning, until the stress-COD curve of the same specimen, as measured during the pre-cracking test on the virgin undamaged sample is met. The new value of the "origin" COD can be estimated by drawing, from the aforementioned point on the curve of the virgin sample, an unloading branch with a slope equal to that of the unloading previously measured on the virgin sample itself. This allows to define and calculate an Index of Crack Healing:

$$
\mathrm{ICH}=\frac{\mathrm{COD}_{\text {pre-cracking }}-\mathrm{COD}_{\text {post-conditioning }}}{\mathrm{COD}_{\text {pre-cracking }}}
$$

From the trends of ICH vs. immersion time (Figure 8), the following remarks hold:

- a remarkable crack closure may occur, since from the beginning of the surveyed exposure times, for specimens containing the crystalline additive and immersed in water; the same specimens, when exposed to air, show a slower recovery capacity;

- immersion in water triggers the self healing also for specimens without any additive, but at a much slower pace: only after 2 to 3 months effects start being visible and after 6 months a performance comparable to specimens with the additive was achieved; specimens without any additive exposed to air hardly show any appreciable recovery and only after prolonged exposure a moderate crack closure starts appearing.

The trends of indices of recovery of mechanical properties vs. the related crack healing indices allow an insightful synopsis to be provided about the investigated phenomena as well as a preliminary methodological quantification to be attempted. Effects of exposure conditions and of the crystalline additive are evident. Moreover it can be highlighted that the trend of damage recovery vs. crack healing (Figure 9a), shows that a remarkable crack healing is needed in order to have an appreciable recovery of the specimen stiffness. Effects of crystalline additive in the concrete mix is also evident, from the higher levels of recovery of stiffness for equal healing of the cracks. On the other hand, the trend of the load recovery vs. crack healing (Figure 9b) shows that some load bearing capacity is recovered even for very low values of estimated crack healing, with a more moderate influence of the additive, also considering the narrow data range provided by experiments. The captured trend is slower than the stiffness recovery one and hardly more than $20 \%$ of the stress decay experienced upon cracking could be garnered because of the crack healing. A better understanding could be achieved through a dedicated analysis of the strength development of crack healing products, as also affected by exposure conditions, which has been regarded as out of the scope of this work. 


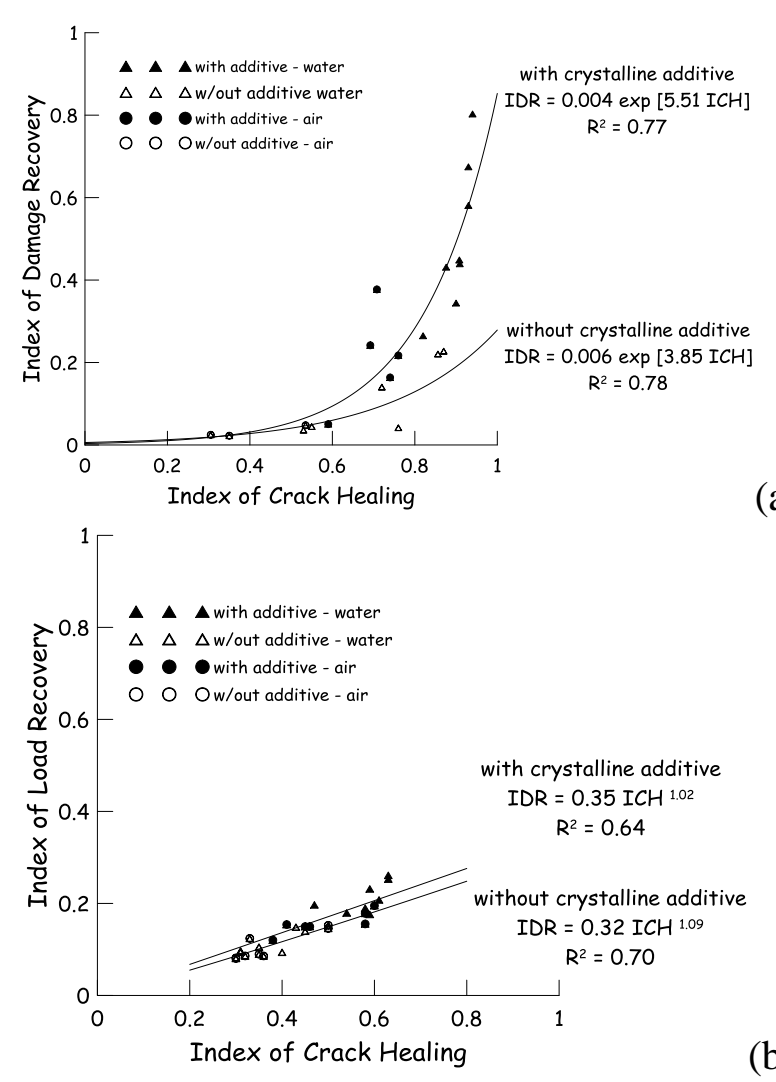

(a)

Figure 9: Index of Damage Recovery (a) and Index of Stress Recovery (b) vs. Index of Crack Healing.

\section{NUMERICAL MODELLING}

\subsection{Self-healing modelling}

Despite the remarkable experimental evidence produced about the efficacy of several self-healing techniques, still a fundamental step needs to be tackled in order to promote a reliable incorporation of selfhealing concepts into design approaches for civil engineering structures and infrastructures. This deals with the predictive modelling of self-healing and its engineering outcomes.

The SMM model [38] for concrete, which makes use of the micro-plane model M4 and the solidification-micro-prestress theory, is able to reproduce, as demonstrated, all the major effects of concrete behavior, such as creep, shrinkage, thermal deformation, aging, and cracking starting from the initial stages of its maturing up to the age of several years. The moisture and heat fields, as well as, the hydration degree are obtained from the solution of the hygro-thermal-chemical problem $[39,40]$.
This model has been extended for incorporating the self-healing effects introducing an internal variable which characterize the self-healing process, the effects of cracking on the diffusivity, and the opposite repairing effect of the self-healing on the mechanical model.

The overall self-healing process can be approximately described by a normalized overall reaction extent $\lambda_{\text {sh }}$ called self-healing recovery degree. This variable characterizes the evolution of the healing repairing process with $\lambda_{\mathrm{sh}}=0$ at the beginning and $\lambda_{\mathrm{sh}}=1$ at the full completion of the process. The selfhealing recovery degree describes the effects of healing on the regain of the strength after its reduction due to damage/cracking (strength restoration). This means that if $\lambda_{\mathrm{sh}}=1$ at the end of the process the material recovers completely from damage/cracking deterioration as a virgin material.

The driving force of this overall healing process is the reaction affinity $\mathrm{A}_{\mathrm{sh}}\left(\lambda_{\mathrm{sh}}\right)$ that can reasonably be assumed to decrease progressively from an initial affinity $\mathrm{A}_{\mathrm{sh}}\left(\lambda_{\mathrm{sh}}=\right.$ $0)=A_{\text {sh0 }}$ that starts the reaction to equilibrium state $\mathrm{A}_{\mathrm{sh}}\left(\lambda_{\mathrm{sh}}=0\right)=0$.

Assuming the affinity to vary linearly:

$$
\mathrm{A}_{\mathrm{sh}}\left(\lambda_{\mathrm{sh}}\right)=\mathrm{A}_{\mathrm{sh} 0}\left(1-\lambda_{\mathrm{sh}}\right)
$$

Furthermore, a linear relationship is adopted between the reaction rate $\dot{\lambda}_{\text {sh }}$ and the reaction affinity

$$
\mathrm{A}_{\mathrm{sh}}\left(\lambda_{\mathrm{sh}}\right)=\mathrm{k}_{\mathrm{sh}} \dot{\lambda}_{\mathrm{sh}}
$$

where $\mathrm{k}_{\mathrm{sh}}$ is a kinetic coefficient.

Substituting $A_{\text {sh }}(\lambda$ sh $)$ in Eq. 4 a first order reaction kinetic law is obtained:

$$
\dot{\lambda}_{\text {sh }}=\tilde{A}_{\text {sh }}\left(1-\lambda_{\text {sh }}\right)
$$

where $\tilde{A}_{\mathrm{sh}}=\mathrm{A}_{\mathrm{sh} 0} / \mathrm{k}_{\mathrm{sh}}$ represents the driving force of the overall self-healing recovery process. To set up a reasonable and physically sound expression for Ash one has to consider that, as it is explained in detail in the Introduction section, the self-healing process actually depends on several different factors, including material compositions, initial crack width, sustained through crack stress and exposure conditions. 
In agreement with the aforementioned statements, we can express the reaction affinity as follows:

$$
A_{s h}=A_{s h 0} f_{h}(h) f_{w}\left(w_{c}\right) e^{-E s h / R T}
$$

where $E_{\text {sh }}$ is the self-healing activation energy, $\mathrm{R}$ is the universal gas constant, and $\mathrm{T}$ the current absolute temperature. The coefficient $\mathrm{A}_{\text {sho }}$ takes into account the effect of the initial un-hydrated cement and the possible presence of the admixture:

$$
\mathrm{A}_{\mathrm{sh} 0}=\mathrm{A}_{\mathrm{sh} 1}\left(\alpha_{\mathrm{c}, 0}-\alpha_{\mathrm{c}, \infty}\right) \mathrm{c}+\mathrm{A}_{\mathrm{sh} 2} a d
$$

where $\alpha_{c, 0}$ is the value of un-hydrated cement when the healing process starts and $\alpha_{c, \infty}$ is the asynmptotic value of the same parameter, c is the cement content, $a d$ is the content of healing-boosting additive, and $\mathrm{A}_{\text {sh } 1}$ and $\mathrm{A}_{\mathrm{sh} 2}$ are two material parameters to be calibrated.

It is well known from experiments the importance of water or high level of relative humidity to have the self-healing activity, which below a certain value decreases and may be even zero. This is taken into account by means of the function $f_{h}(h)$, with $h$ degree of relative humidity, also used in the definition of the hydration degree and expressed as:

$$
\mathrm{f}_{\mathrm{h}}(\mathrm{h})=\frac{1}{1+5.5(1-\mathrm{h})^{4}}
$$

The effect of the initial value of the crack width is reproduced by the function $\mathrm{f}_{\mathrm{w}}\left(\mathrm{w}_{\mathrm{c}}\right)$, which is defined as follows:

$\mathrm{f}_{\mathrm{w}}\left(\mathrm{w}_{\mathrm{c}}\right)=\left\{1+\left[\mathrm{a}_{\mathrm{w}}-\mathrm{a}_{\mathrm{w}}\left(1-\mathrm{w}_{\mathrm{c}}\right)\right]^{\mathrm{bw}}\right\}^{-1}$

where the coefficients $a_{w}$ and $b_{w}$ are two free parameter.

The expression of the function in Eq. 9, plotted in Figure 10, has been formulated on the basis of experimental data on the maximum crack width that can be healed by autogenous healing. This was observed to differ substantially among reports made by various authors, i.e., 5 to $10 \mu \mathrm{m}[17,18]$, up to $100 \mu \mathrm{m}$ [16], $200 \mu \mathrm{m}$ [13], and $300 \mu \mathrm{m}$, confirming that narrower cracks are more likely to be completely healed by autogenous healing.

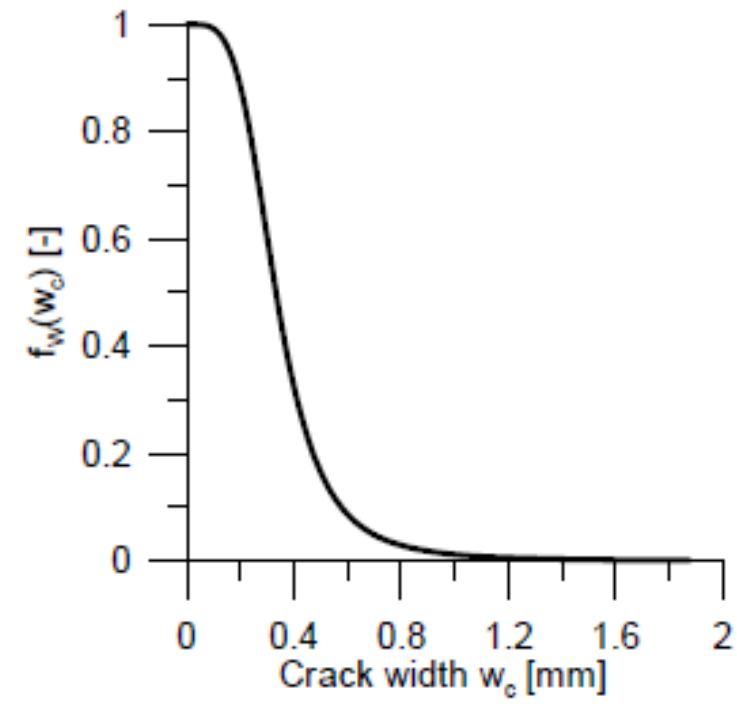

Figure 10: Effect of the crack opening on the affinity reaction.

\subsection{Simulation results}

With the model recalled above, and for which only the self-healing modelling assumptions have been herein reported for the sake of brevity, the experimental process described in Section 3 has been simulated. Reference has been herein made to both autogenous healing and healing engineered through the use of the crystalline admixture.

Temperature, relative humidity, degree of hydration, and self-healing recovery degree are obtained by solving the hygro-thermochemical problem imposing the environmental conditions before and after the pre-cracking, as described above. In Figure 11 the evolution of the relative humidity for the specimen kept in water after the pre-cracking is shown. The comparison between the experimental and the numerical results in terms of the load vs. COD response is reported in Figures 12 and 13 for the concrete mixture without and with the additive, respectively. A recovery of the load bearing capacity, with respect to the unloading value at which pre-cracking was performed in the first stage, is evident, obviously depending on mix composition and exposure duration.

The agreement between experimental results and numerical predictions of the model is actually remarkable for the whole set of simulated experimental cases, highlighting the reliability and versatility of the modelling approach formulated as above. 


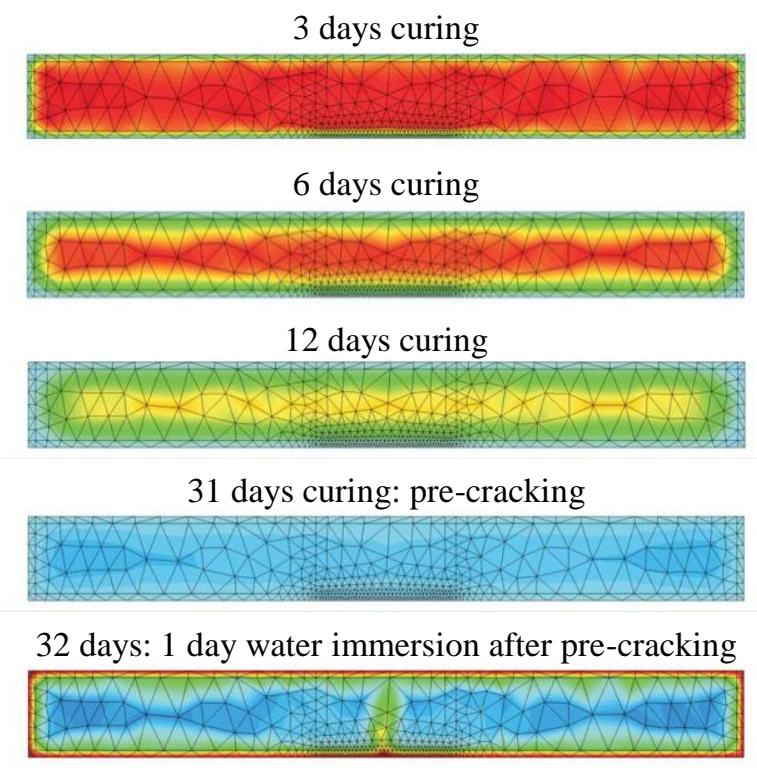

60 days. 29 days water immersion after precracking
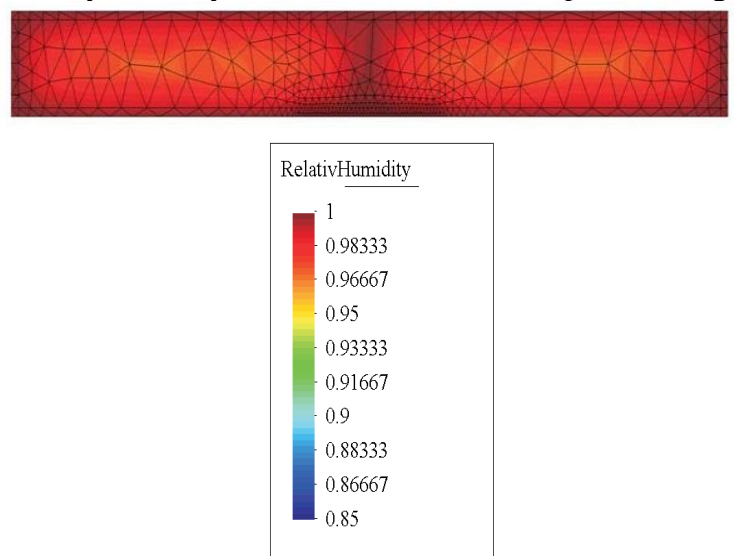

Figure 11: evolution of the relative humidity evolution in the the specimen during the healing process

\section{CONCLUSIONS}

A study has been herein presented on the self-healing capacity of normal strength concrete, both autogenous and engineered through the use of a crystalline admixture. The capacity of the material to completely or partially re-seal cracks and, in case, also induce recovery of mechanical properties has been investigated, with reference to two different exposure conditions. By means of three-point-bending tests performed up to controlled crack opening and up to failure, respectively before and after conditioning, the recovery of stiffness and stress bearing capacity has been evaluated.

A model for predictive simulation of the self-healing capacity of cementitious composites and of the associated recovery of mechanical performance has been formulated and validated. The SMM model for concrete has been modified for incorporating the effects of self-healing, by introducing a self-healing reaction affinity function, which depends on relative humidity and crack width, and explicitly includes both autogenic and engineered healing. The numerical examples shown highlight the capacity of the model to properly describe the evolution of the crack healing along with conditioning time and its effects on the recovery of the mechanical properties.

Though a more extensive calibration with reference to different exposure conditions and mix compositions is needed, the model may represent a valuable asset to proceed along with the consistent incorporation of selfhealing concepts and effects into design approaches, for both new and retrofitted structures employing self-healing cement based materials.

\section{ACKNOWLEDGEMENTS}

The authors acknowledge the financial contribution of Politecnico di Milano, Giovani Ricercatori 2011 grant. The financial support of Penetron International Ltd. and Penetron Italia srl to the experimental campaign is also gratefully acknowledged.

\section{REFERENCES}

[1] Mihashi, H and Nishiwaki, T. 2012. Development of engineered self-healing and self-repairing concrete. State-of-art report. Journal of Advanced Concrete Technology 10: 170-184.

[2] Tittelboom, K.V. and De Belie, N. 2013. Self-healing in cementitious materials - A review. Materials, 6: 2182-2217.

[3] Lauer, K.R. and Slate, F.O. 1956. Autogeneous healing of cement paste. ACI Journal 52: 1083-1097.

[4] Bertolini, L., Elsener, B., Pedeferri, P. and Polder, R. 2003. Corrosion of steel in concrete: prevention, diagnosis, repair. Wiley.

[5] Abrams, D.A. 1913. Tests of bond between concrete and steel, University of Illinois Bulletin 71, 107 pp. 

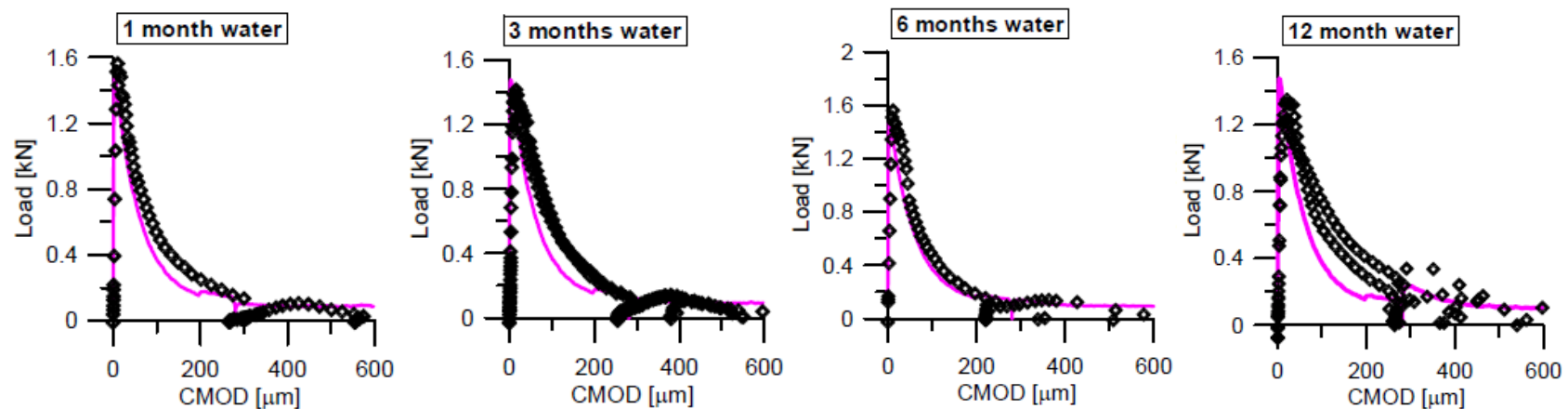

Figure 12: numerical (dots) vs. experimental (solid line) comparison recovery of mechanical properties - concrete specimens without crystalline admixture in water.
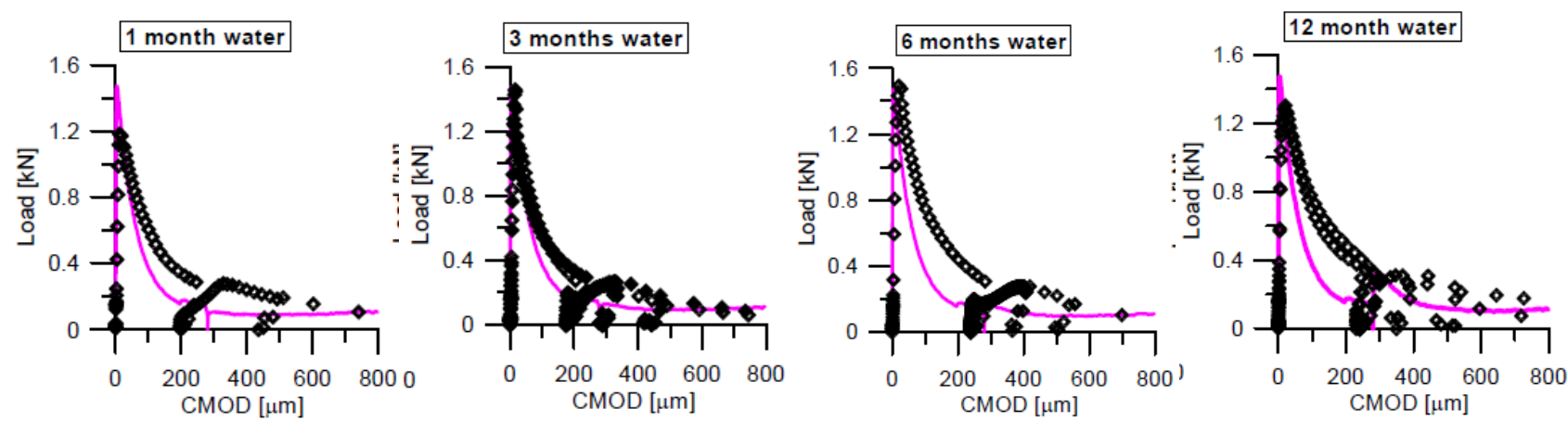

Figure 13: numerical (dots) vs. experimental (solid line) comparison recovery of mechanical properties - concrete specimens with crystalline admixture in water.

[6] Loving, M.W. Autogenous healing of concrete. 1936. American Concrete Pipe Association. Bullettin 13.

[7] Ramm, W. and Biscoping, M. 1998. Autogeneous healing and reinforcement corrosion of water-penetrated separation cracks in reinforced concrete. Nuclear Engineering and Design 179: 191-200.

[8] Hearn, N. and Morley, C.T. 1997. SelfSealing Property of Concrete: Experimental Evidence. Materials and Structures 30: 404-411.

[9] Neville, A. 2002 Autogenous Healing: a concrete miracle? Concrete Intl.24: 76-82.

[10] Turner, L. 1937. The autogenous healing of cement and concrete: its relation to vibrated concrete and cracked concrete. IATM London Congress: 344.

[11] Whitehurst E. 1951. Soniscope tests concrete structures. ACI Journal 47: 433-444.

[12] Hearn N. 1998. Self-Sealing, Autogenous Healing and Continued Hydration: What is the Difference? Materials and
Structures 31: 563-567.

[13]Edvardsen, C. 1999. Water permeability and autogenous healing of cracks in concrete. ACI Materials Journal 96: 448-454.

[14] Aldea, C.M., Song, W.J. and Popovics, J.S. 2000. Extent of healing of cracked NSC, ASCE Journal of Materials in Civil Engineering 2: 92-96.

[15]Dhir, R.K., Sangha C.M. and Munday J.G. 1973. Strength and Deformation Properties of Autogenously Healed Mortars. ACI Journal 70: 231-236.

[16]Reinhardt, H.W. and Jooss, M. 2003. Permeability and self-healing of cracked concrete as a function of temperature and crack width. Cement and Concrete Reseach 33: 981-985.

[17]Jacobsen, S., Sellevold, E.J. 1993. Self healing of high strength concrete after deterioration by freeze/thaw. Cement and Concrete Research 26: 55-62.

[18] Sahmaran, M., Keskin, S.B., Ozerkan, G., Yaman, I.O. 2008. Self-healing of 
mechanically loaded SCCs with high volumes of fly ash, Cement and Concrete Composites 30: 872-879.

[19]Ngab, A.S., Nilson A.H. and Slate, F.O. 1981. Shrinkage and creep of high strength concrete. ACI Journal 78: 225261.

[20]Hannant, D.J. and Keer, J.G. 1983. Autogenous healing of thin cement-based sheets. Cement and Concrete Research 13: 357-365.

[21]Grey, D.J. 1984. Autogenous healing of fiber/matrix interfacial bond in fiber reinforced mortar. Cement and Concrete Research 14: 315-317.

[22] Yang, Y., Lepech, M.D., Yang, E.H. and Li, V.C.. 2009. Autogenous healing of ECCs under wet-dry cycles. Cement and Concrete Research 39: 382-390.

[23]Qian, S., Zhou, J., de Rooji, M.R, Schlangen, E., Ye, G. and van Breugel, K. 2009. Self-healing behavior of SHCCs incorporating local waste materials. Cement and Concrete Composites 31: 613-621.

[24]Qian, S.Z., Zhou, J. and Schlangen, E. 2010. Influence of curing condition and precracking time on the self-healing behavior of ECCs. Cement and Concrete Composites 32: 686-693.

[25] Yang, Y., Yang, E.H. and Li, V.C. 2011. Autogeneous healing of ECCs at early age. Cement and Concrete Research 41, 176-183.

[26]Li, M. and Li, V.C. 2011. Cracking and healing of engineered cementititous composites under chloride environment, ACI Materials Journal 108: 333-340.

[27]Ferrara, L., Ferreira, S.R., Krelani, V., Silva, F. and Toledo Filho, R.D. 2014. Effect of natural fibres on the self healing capacity of HPFRCCs. In E. Schlangen et al. (Eds.) Proceedings SHCC3, pp. 9-16.

[28] Mihashi, H., Ahmed, S.F.U. and Kobayakawa, A. 2011. Corrosion of reinforcing steel in Fiber Reinforced Cementitious Composites. Journal of Advanced Concrete Technology 9: 159-167.

[29] Jonkers, H.M. 2010. Bacteria based selfhealing concrete. Heron 56 (1/2): 1-12.
[30]RILEM TC 225-SAP. 2012. Application of SAP in Concrete Construction, State of the Art Report. V. Mechtcherine and H.W. Reinhardt eds., Springer, X, 166 p.

[31] Van Tittelboom, K., De Belie, N., Van Loo, D. and Jacobs, P. 2011. Self-healing efficiency of cementitious materials containing tubular capsules filled with healing agent. Cement and Concrete Composites 33, 497-505.

[32] Yang, Z., Hollar, J., He, X. and Shi, X. 2011. A self-healing cementitious composite using oil/core silica gel shell microcapsules. Cement and Concrete Composites 33: 506-512.

[33]ACI 212-3R-10. 2010. Report on chemical admixtures for concrete. 61pp.

[34] Termkhajornkit, P., Nawa, T., Yamashiro, Y. and Saito, T. 2009. Self-healing ability of fly ash-cement systems. Cement and Concrete Composites 31: 195-203.

[35] Sisomphon, K. ad Copuroglu, O. 2011. Self-healing mortars by using different cementitious materials. Proceedings Advances in construction materials through science and engineering.

[36] Carsana, M., Frassoni, M., Bertolini, L. 2014. Comparison of ground-waste-glass with other supplementary cementitious materials. Cement and Concrete Composites 45: 39-45.

[37]Bertolini, L., Carsana, M., Frassoni, M. and Gelli, M. 2011. Pozzolanic additions for durability of concrete structures, Construction Materials ICE 164: 283-291.

[38]di Luzio, G. and Cusatis G. 2009. Hygrothermo-chemical modeling of HPC. I: Theory. Cement and Concrete Composites 31: 301-308.

[39] di Luzio, G. and Cusatis G. 2009. Hygrothermo-chemical modeling of HPC. II: Numerical implementation, calibration, and validation. Cement and Concrete Composites 31: 309-324.

[40]di Luzio, G. and Cusatis G. 2013. Solidification microprestress- microplane (SMM) theory for concrete at early age: theory, validation and application. International Journal of Solids and Structures 50: 957 - 975. 